\title{
Martha Rodríguez Achung, Naro matsigenka. Territorio, comunidad y acceso a los recursos de la biodiversidad. Lima, Fondo Editorial PUCP, 154 pp., 2016
}

\author{
Fernando H. Roca Alcazar*
}

El libro dela doctora Martha RodríguezAchung, socióloga, nos presenta un trabajo en el que logra mostrar el conocimiento detallado de un pueblo amazónico en sus relaciones con el entorno en el que viven y también la gran flexibilidad adaptativa con las correspondientes respuestas culturales que desarrollan. Ello se da en contextos complejos, de cambios constantes, sea por presiones externas o por desafíos internos. No es solo el arte de la resiliencia adaptativa sino también el arte de responder con creatividad. Como afirmó en el prólogo de su libro: «...la producción de saberes no se detiene, la capacidad de resiliencia sigue vigente, la preocupación por el manejo y uso de sus recursos se mantiene. Para ellos, la relación con su entorno natural sigue siendo fundamental porque es parte de ellos mismos, bosques y cuerpos de agua son parte de su piel, de sus vidas» (p. xiii).

Luego de la presentación, el prólogo y la introducción, desarrollada esta última con mucha claridad por la autora, encontramos cuatro capítulos que nos llevan desde el espacio del encuentro e historia con los orígenes de un pueblo (Desplazamientos y encuentros: de la dispersión a la comunidad) a la descripción de la vida cotidiana matsigenka (Matsigenkas: una sociedad de pescadores). Seguidamente, la investigadorase centra en los «territorios» de lo femenino (Recolección: diversidad de la canasta matsigenka y espacio de disfrutey recreación) y lo masculino (El arte dela caza: espacio de construcción de la masculinidad). El epílogo del libro nos abre desde los tiempos

\footnotetext{
* Profesor principal del Departamento de Comunicaciones y de la Maestría de Altos Estudios Amazónicos, Pontificia Universidad Católica del Perú (PUCP). Correo electrónico: froca@pucp.pe
} 
actuales hacia los desafíos de un futuro de características particulares. Es el futuro de un pueblo amazónico con su territorio ancestral en cuyas entrańas se encuentra el mayor yacimiento gasífero del Perú, un pueblo que crea y desarrolla nuevos lazos y contactos con el estado, con su entorno, con actores nuevos que irrumpen en su historia. El rigor académico aparece articulado con el reconocimiento (homenaje en palabras de la autora) al grupo humano con el que la investigadora compartió su vida durante varios ańos de trabajo de campo.

Me parece necesario destacar la estructura cuatripartita que la autora le ha dado al libro: ubica primero histórica y espacialmente al grupo humano con el que trabajó y compartió durante tanto tiempo, destacando su capacidad de asociarse con otros grupos vecinos y al mismo tiempo la gran movilidad territoral que muestra «...abarcando un espacio entre varias cuencas hidrográficas, el Alto Manu al este, el Madre de Dios al sur, y pasando el Vilcabamba llegaron al río Ene y Apurímac al oeste y el río Mishagua, que desemboca en el gran Eni o Urubamba, hacia el norte» (p. 9).

Luego desarrolla una característica básica del grupo naro matsigenka, su relación con los cuerpos de agua y la pesca como elemento cultural articulador con los mismos. Desde las pequeñas quebradas y cochas, hasta los grandes ríos que discurren por el territorio. La detallada descripción de los recursos ictiológicos existentes y de la conservación de estos cuerpos de agua, muestran con claridad un aspecto importante de las relaciones hombre-naturaleza para el caso específico de este pueblo originario y cómo la importancia de conservar la «vida del agua» y de los seres que la habitan es fundamental para conservar la vida del mismo pueblo que se relaciona con ella. Las actuales contaminaciones de las cabeceras y cursos hídricos de nuestra Amazonía ponen en riesgo la calidad de vida y la vida misma de estos pueblos originarios.

Los dos últimos capítulos se centran, en dos temas, recolección y caza.

En las actividades de recolección, destaca los productos comestibles de los no comestibles, poniendo énfasis en los primeros. Si bien es cierto que «...la recolección, al igual que la pesca, es una actividad realizada por todos los miembros de la familia» (p. 69), coincido con la autora cuando afirma que «...constituye para las mujeres un espacio de encuentro entre ellas, de caminatas por el bosque y recreación familiar, un espacio para explayarse, para los intercambios de experiencias cotidianas entre pares y el disfrute de sabores diversos y frescos de los frutos del bosque» (p. 93). Más aún el arte femenino de recolectar contribuye muchas veces con mayores aportes a la canasta familiar que las de su par masculino. La «lógica compensatoria» en palabras de la autora (p. 70) permite que el aporte de los productosictiológicos, siempre mayor, sea complementado con estos otros del bosque, fruto de la recolección, a los que también se suman los de la caza y la horticultura. El «arte de recolectar» supone un conocimiento del ecosistema y de las interrelaciones que en él se dan. Nuevamente se describen con detalle las formas culturales de recolectar (escuchar el tronco, 
no extraer árboles semilleros, identificar las distintas zonas de recolección, dejar que en la chacra crezcan especies no cultivadas pero útiles para el consumo o el uso doméstico, diferenciar entre territorios de uso comunitario con bienes comunes y los de uso de las chacras pertenecientes a familias, identificar la estación de lluvias como la de mayor peso para la recolección, la descripción de las herramientas utilizadas y la función básica de autoconsumo que ofrece esta práctica). Al igual que en la pesca, menciona y describe los principales productos recolectados del bosque y el uso cultural de los mismos.

La caza la ubica en el espacio de construcción de la identidad masculina, ofreciéndose como el complemento de lo femenino. Las tablas y los cuadros nos ofrecen datos interesantes sobre porcentajes sistematizados, de biomasa por espacios y épocas del año determinadas por el río, por cantidades de peso obtenidas anualmente según diversos períodos. Estos cuadros y tablas también aparecen en los capítulos anteriores sistematizando una serie de importantes informaciones. El varón reconoce los territorios de caza, con sus distintas características, los períodos y la diversidad de fauna así como las características de la misma.

El epílogo, como indiqué al inicio, cierra el libro pero se abre hacia el futuro con los nuevos desafíos que se presentan a las comunidades: mayor presencia de actividades e industrias extractivas y productivas, ofrecimiento de empleo estable con demanda de mano de obra, creación de nuevas demarcaciones políticas. Frente a ello la autora afirma «...la continuidad en las actividades de caza, pesca y recolección propias de la tradición del pueblo matsigenka, como espacios individuales y familiares de socialización y transmisión de la herencia social, escenarios para aprender haciendo y constituirse como sujetos en comunidad» (p. 146).

Es el anuncio de un pueblo capaz de abrirse hacia el siglo XXI y que sabe anclarse en lo más profundo de su identidad, para seguir siendo lo que saben que son y al mismo tiempo dialogar con lo nuevo que viene.

El libro de la doctora Rodríguez bien merece la pena leerse y reflexionarse pausadamente, a ello nos ayudan el elaborado discurso científico que ofrece, el testimonio directo del pueblo que aparece como protagonista, el abundante registro fotográfico y el corto que lo acompaña en formato de DVD en donde son los matsigenka los actores principales. Podemos así acercarnos a las orillas culturales de pueblos cuyo conocimiento y prácticas ancestrales tienen aún que aportar mucho en la construcción de nuestra identidad como país, un "Perú de todas las sangres» parafraseando a José María Arguedas. 


\section{Indicaciones para los autores}

1. Debates en Sociología acepta tres tipos de contribuciones: investigaciones, ensayos y reseñas/comentarios. Los envíos a la revista deben ser trabajos originales que no estén siendo evaluados para publicación en otras editoriales. Los artículos serán evaluados preliminarmente por la dirección editorial, luego, serán enviados a revisores académicos de forma anónima. Estos lo juzgarán en función de los siguientes criterios: originalidad de la aproximación, sustento teórico a la argumentación, calidad de la metodología y uso de la información, claridad y coherencia del artículo. Los comentarios serán devueltos en un plazo máximo de dos meses. Los revisores pueden rechazar el artículo, aceptarlo como está, pedir revisiones menores, o revisiones mayores. La versión revisada debe incluir respuestas a los comentarios de los revisores. En el caso de los ensayos y reseńas se evaluará fundamentalmente la claridad en la argumentación y el respaldo de las ideas.

2. En la primera página se debe incluir el título del escrito, el nombre de cada autor, correo electrónico, grados académicos y afiliaciones institucionales actuales. Opcionalmente en esta sección se deben incluir los agradecimientos. En el caso de las investigaciones y ensayos, en la segunda página se debe incluir en castellano e inglés: título, resumen de máximo 150 palabras y de 3 a 5 palabras clave.

3. La revisión de los escritos es anónima, por lo que los autores no deben hacer mención a su identidad en el cuerpo del escrito. A partir de la segunda página no se debe incluir ninguna referencia explícita o tácita a la autoría del escrito.

4. En extensión las investigaciones y ensayos no deben sobrepasar las 12000 palabras, incluyendo notas, tablas, apéndices y referencias bibliográficas. En el caso de las reseñas y comentarios, deben tener como máximo 1500 palabras.

5. El texto debe estar justificado con tipo de letra Times New Roman tamaño 12, espacio de interlineado 1,5 , con márgenes de $2,5 \mathrm{~cm}$ superior e inferior y $2,5 \mathrm{~cm}$ a los lados. A lo largo del texto se utilizará la coma para decimales, con un máximo de tres decimales (por ejemplo: 0,048). Al escribir números de más de cuatro cifras, se agruparán estas de tres en tres, y separando los grupos por espacios en blanco (por ejemplo: 56 917).

6. Los cuadros (tablas, gráficos e ilustraciones) deberán estar insertados en el cuerpo del texto. Cada cuadro debe ser encabezado por una numeración única a lo largo del documento $(1,2,3 \ldots)$ y un título breve, únicamente con subrayado simple. Todos los cuadros deben indicar la fuente de los datos y de su elaboración. Las tablas deben incluir una descripción mínima para cada columna y fila.

7. Debates en Sociología sigue el sistema de citación autor-año, estilo APA. Toda citación debe estar inserta en el texto y detallada al final del documento, en la lista de referencias. No deben usarse abreviaturas del tipo «loc. cit.», «op. cit.», «ídem», «ibíd.»; por otra parte, en la primera aparición solo debe usarse «et al.» para documentos con seis o más autores. A continuación presentamos ejemplos de las dos formas de citar en el texto. 


\begin{tabular}{|l|l|}
\hline Forma 1 & Forma 2 \\
\hline Dubet y Martuccelli (1998) & (Dubet y Martuccelli, 1998) \\
\hline Dubet y Martuccelli (1998, p. 121) & (Dubet y Martuccelli, 1998, p. 121) \\
Dubet y Martuccelli (1998, pp. 52-54) & (Dubet y Martuccelli, 1998, pp. 52-54) \\
\hline Lareau (2002, 2003), Montero (1995) & (Lareau, 2002, 2003; Montero, 1995) \\
\hline
\end{tabular}

Para mayor información sobre el estilo, por favor consultar el manual de estilo APA (sexta edición). Para aspectos básicos, recomendamos la siguiente página: http://flash1r. apa.org/apastyle/basics/

8. Al final del escrito se debe incluir una lista de referencias completas, ordenada alfabéticamente según el primer apellido del autor. Las referencias deben contener el apellido y las iniciales de todos los autores del documento. Todas las fuentes citadas en el texto deben estar en la lista de referencias y viceversa. Presentamos algunos ejemplos a continuación.

Libro

Dubet, F. y Martuccelli, D. (1998). En la escuela. Sociología de la experiencia escolar. Buenos Aires: Losada Editores.

Capítulo en libro

Montero, C. (1995). Ciclos de vida y tiempos de escuela: el caso de las mujeres en el Perú. En S. Bourque, C. Montero y T. Tovar (eds.), ¿Todos igualitos? Género y educación (pp. 43-66). Lima: Pontificia Universidad Católica del Perú.

ARTí́culo

Beck, A., Epstein, N., Brown, G. y Steer, R. (1988). Un inventario para medir la ansiedad clínica: propiedades psicométricas. Revista de Psicología Clínica, 56, 893-950.

Lareau, A. (2002). Invisible inequality: Social class and childbearing in black families and white families. American Sociological Review, 67, 747-776.

Documento EN LA WeB

Tremblay, R., Nagin, D. y Petitclerc, A. (2008). Prevenir la violencia a través del aprendizaje de la primera infancia. Recuperado de http://www.excellence-earlychildhood. $\mathrm{ca} /$ documents/tremblay05.pdf

9. Las notas a pie de página deben ser utilizadas para comentarios cortos y sustantivos. Se pueden incluir anexos al final del texto con información adicional.

10. Los textos deben estar en MS Word y deben enviarse únicamente al correo electrónico institucional de la revista.

11. La ética en los procedimientos y contenidos es responsabilidad expresa de los autores. La rigurosidad en la citación de fuentes es un requisito indispensable para participar en el proceso de selección de escritos. Se deberán realizar los procedimientos de certificación de originalidad de escritos y liberación de derechos, para lo que se brindará la información una vez iniciado el proceso editorial.

Consulta y recepción de trabajos: revistadebates@pucp.edu.pe 